\title{
CYP1A1 methylation mediates the effect of smoking and occupational polycyclic aromatic hydrocarbons co-exposure on oxidative DNA damage among Chinese coke-oven workers
}

Yanli Liu ${ }^{1,2}$, Xuejing Li ${ }^{1}$, Bin Zhang ${ }^{1}$, Ye Fu ${ }^{1}$, Aimin Yang ${ }^{3}$, Hongjie Zhang ${ }^{1}$, Huitao Zhang ${ }^{1}$, Yingying Niu', Jisheng $\mathrm{Nie}^{1}$ and Jin Yang ${ }^{1 *}$ (D)

\begin{abstract}
Background: Multiple factors, including co-exposure between lifestyle and environmental risks, are important in susceptibility to oxidative DNA damage. However, the underlying mechanism is not fully understood. This study was undertaken to evaluate whether Cytochrome P4501A1 (CYP1A1) methylation can mediate the co-exposure effect between smoking and occupational polycyclic aromatic hydrocarbons (PAH) in development of oxidative DNA damage.

Methods: We explored the associations between smoking and occupational PAH co-exposure effect, CYP1A1 methylation and oxidative DNA damage among 500 workers from a coke-oven plant in China. Urine biomarkers of PAH exposure (1-hydroxypyrene, 1-OHP; 2-hydroxynaphthalene, 2-NAP; 2-hydroxyfluorene, 2-FLU; and 9hydroxyphenanthren, 9-PHE) and a marker of oxidative DNA damage (8-hydroxy-2'- deoxyguanosine, 8-OHdG) were measured by high performance liquid chromatography. CYPIA1 methylation was measured by pyrosequencing. Finally, mediation analysis was performed to investigate whether CYP1A1 methylation mediated smoking and occupational PAH co-exposure effect on oxidative DNA damage.

Results: We observed significant associations of smoking and 1-OHP cO-exposure with CYP1A1 hypomethylation (OR: 1.87, 95\% Cl: 1.01-3.47) and high 8-OHdG (OR: 2.13, 95\% Cl: 1.14-3.97). There was a significant relationship between CYP1A1 hypomethylation and high 8-OHdG (1st vs. 3rd tertile $=1.58,95 \% \mathrm{Cl}: 1.01-2.47$, P for trend $=0.046$ ). In addition, mediation analysis suggested CYP1A1 hypomethylation could explain 13.6\% of effect of high 8-OHdG related to smoking and 1-OHP co-exposure.
\end{abstract}

Conclusions: Our findings suggested that the co-exposure effect of smoking and occupational PAH could increase the risk of oxidative DNA damage by a mechanism partly involving CYP1A1 hypomethylation.

Keywords: Oxidative DNA damage, Polycyclic aromatic hydrocarbons, Smoking, Cytochrome P4501A1, DNA methylation

\footnotetext{
* Correspondence: yang_jin@sxmu.edu.cn

${ }^{1}$ Department of Occupational Health, School of Public Health, Shanxi Medical

University, Taiyuan, Xinjiannan Road 56, Taiyuan 030001, Shanxi, China

Full list of author information is available at the end of the article
}

(C) The Author(s). 2019 Open Access This article is distributed under the terms of the Creative Commons Attribution 4.0 International License (http://creativecommons.org/licenses/by/4.0/), which permits unrestricted use, distribution, and reproduction in any medium, provided you give appropriate credit to the original author(s) and the source, provide a link to the Creative Commons license, and indicate if changes were made. The Creative Commons Public Domain Dedication waiver (http://creativecommons.org/publicdomain/zero/1.0/) applies to the data made available in this article, unless otherwise stated. 


\section{Introduction}

Oxidative DNA damage induced by reactive oxygen species (ROS) plays a pivotal role in the nosogenesis of respiratory disease such as lung cancer and asthma $[1,2]$. ROS, resulting from chemical compounds or the action of exogenous physical factors such as ultraviolet A, or the metabolism of cells, can induce a great many DNA damage, including base modification and DNA strand breaks [3], were generally believed to be involved in the carcinogenic mechanism $[4,5]$. Previous studies have shown that 8-hydroxy- 2' - deoxyguanosine (8-OHdG) is a widely accepted biomarker for assessing the extent of oxidative damage to DNA [6]. Lifestyle environmental factors, such as smoking [7-9] and polycyclic aromatic hydrocarbons (PAH) exposure [10, 11], have been proved to relate with urine 8-OHdG levels.

Smoking has a strong effect on oxidative DNA damage, and PAH exposure is also related to oxidative DNA damage among occupational workers and general population [11-14]. There is a dose-dependent relationship of smoking and $\mathrm{PAH}$ metabolites in the risk of oxidative damage to DNA [15]. However, a challenge remains to fully understand the molecular mechanism of lifestyle environmental factors between smoking and occupational PAH co-exposure effect on oxidative DNA damage.

Epigenetic modifications, for example, DNA methylation, which can be influenced by lifestyle - environmental factors, may provide a possible biological link between risk factors and the disease. Cytochrome P4501A1 (CYP1A1) is answerable for $\mathrm{PAH}$ metabolism, which participated in the metabolic process of exogenous compounds via the excessive formation of ROS $[16,17]$, eventually lead to the oxidative DNA damage. It has also been demonstrated that CYP1A1 can be induced by PAH and cigarette consumption can influence the CYP1A1 methylation levels [18]. Increased lung cancer risk has been associated with high CYP1A1 expression and hypermethylation [19]. Therefore, it's imperative to research whether $C Y P 1 A 1$ methylation could mediate effect of smoking and PAH co-exposure on the development of oxidative damage to DNA.

We hypothesized that the co-exposure effect of smoking and $\mathrm{PAH}$ was involved in the development of oxidative DNA damage via CYP1A1 methylation. To prove our hypothesis, we carried out the research to evaluate the coexposure effect between smoking and $\mathrm{PAH}$ exposure on CYP1A1 methylation and oxidative damage to DNA among coke-oven workers in China, so as to estimate whether CYP1A1 methylation is responsible for increased risk of oxidative DNA damage related to the co-exposure effect of smoking and PAH.

\section{Material and methods}

\section{Study subjects}

The basic demographic data was collected from a cokeoven plant in China by using a cross-sectional survey in
2014. 950 workers participated in the study. We restricted our analyses to who had worked for more than 1 year, and who were non-exposed to known mutagens, for example, chemotherapy and radiotherapy in the last three months. We excluded individuals who were missing with sufficient blood samples $(n=360)$, sufficient urine samples $(n=228)$, or demographic characteristics $(n=278)$. Thus, the final analytic sample was 500 participants, of whom 389 coke-oven workers prolonged exposed to PAH and other 111 water treatment workers in the same plant without exposure to $\mathrm{PAH}$ in the workshop.

Trained interviewers collected the information regarding sex, age, years of working, education, smoking and drinking status, central heating and occupational exposure history by a pre-tested questionnaire. Smokers were defined as those who smoked at least 1 cigarette every day and continuously more than six months, and drinkers were drank at least once a week on average and continuously more than six months. After signing the informed consent, every participant provided with venous blood $(5 \mathrm{~mL})$ and morning urine $(20 \mathrm{~mL})$. And the study was approved by the Medical Ethics Committee of the Shanxi Medical University.

\section{Determination of urine $\mathrm{PAH}$ metabolites}

The morning spot urine samples were collected and freezed at $-80^{\circ} \mathrm{C}$ until further processing. The concentrations of PAH metabolites, including 1-hydroxypyrene (1OHP), 2-hydroxynaphthalene (2-NAP), 2-hydroxyfluorene (2-FLU), and 9-hydroxyphenanthrene (9-PHE) were measured using high performance liquid chromatography (HPLC, Shimadzu Corp, JPN) according to the previously described protocol [20-22]. Urine creatinine $(\mathrm{Cr})$ was measured by spectrophotometry (SpectraMAx M2, Molecular Devices, USA). Valid urine concentrations of PAH metabolites were adjusted using urine $\mathrm{Cr}$ concentrations and are expressed as $\mu \mathrm{g} / \mathrm{mmol} \mathrm{Cr}$. The mean recovery rate, coefficient of variation $(\mathrm{CV}), R$-square and limit of detection (LOD) were 82.97-107.85\%, 2.04-4.27, 0.99981 , and $0.04-0.12 \mu \mathrm{g} / \mathrm{L}$, respectively. The concentrations less than LOD were expressed with half a LOD value.

\section{Urine 8-OHdG measurement}

Urine 8-OHdG was measured by HPLC - electrochemical detector according to Yuan et al. [23] manuscript. In brief, about $2 \mathrm{~mL}$ supernatant of urine was prepared to elute twice with $0.1 \mathrm{~mol} / \mathrm{L} \mathrm{KH}_{2} \mathrm{PO}_{4}$ (PH 6.0), evaporate and dissolve with $1 \mathrm{~mL} \mathrm{KH}_{2} \mathrm{PO}_{4}$. Standard curves of urine 8 -OHdG were run daily to identify and quantify the concentration of urine samples. Valid urine concentrations of 8-OHdG were adjusted using urine $\mathrm{Cr}$ concentrations and are expressed as $\mathrm{mmol} / \mathrm{mol} \mathrm{Cr}$. The 
mean recovery rate, CV, $R$-square and LOD, were $81-$ $105 \%, 3.1,0.9998$, and $7.0 \mathrm{nmol} / \mathrm{L}$, respectively.

\section{CYP1A1 methylation measurement}

DNA was extracted from whole blood according to MagBead blood DNA kit (ComWin Biotech, Beijing, China). The purity and concentration of extracted DNA was detected using ultraviolet and visible spectrophotometer (Eppendorf, Hamburg, Germany). Then bisulfite conversion using EZ DNA methylation Kit (ZYMO Research, California, USA). We choose a $153 \mathrm{bp}$ fragment from 944 to -792 in promoter region of CYP1A1 and 5 CpGs sites as the regions and sites of interest of the converted DNA based on previously published literature on CYP1A1 methylation (Tekpli, 2012). The converted DNA was amplified using TaKaRa EpiTaq HS reagent (Takara, Dalian, China) in $50 \mathrm{~mL}$, which contained $0.25 \mathrm{~mL}$ TaKaRa EpiTaq HS, $5 \mathrm{~mL} 25 \mathrm{mM} \mathrm{MgCl}, 5 \mathrm{~mL} 10 \times$ EpiTaq Polymerase Chain Reaction (PCR) Buffer, $6 \mathrm{~mL}$ dNTP Mixture, $2 \mathrm{~mL} 10 \mathrm{mM}$ forward primer, $2 \mathrm{~mL} 10 \mathrm{mM}$ reverse primer, $100 \mathrm{ng}$ bisulfite DNA and distilled water. Primer sequences for more detailed information could be seen in Additional file 1: Table S1. The PCR program was $95^{\circ} \mathrm{C} 30 \mathrm{~s} ; 95^{\circ} \mathrm{C} 5 \mathrm{~s}, 60^{\circ} \mathrm{C} 30 \mathrm{~s}$, $72^{\circ} \mathrm{C} 30 \mathrm{~s}, 40$ cycles. PCR product was integrated in Streptavidin Sepharose High Performance (GE Healthcare, Sweden) to be purified, washed, denatured and washed again. The washed PCR product was annealed to $0.4 \mathrm{mM}$ of sequencing primer and pyrosequencing was performed using PyroMark Q96 ID System (Qiagen, Hilden, Germany). The methylation degree was expressed as proportion of cytosines that were 5methylated.

During the experiment, the sample of coke oven workers and water treatment workers were arranged alternately. In addition, we set a bisulfite trearment control before the variable positions in dispensation order to judge whether bisulfite treatment completely, and internal controls using PyroMark Control Oligo (Qiagen, Hilden, Germany) to determine if an unexpected result is related to the reagents, to the PyroMark Vacuum Workstations, or to the assay. The peak height of bisulfite control is not more than 7\% of the average single peak height. The lowest single peak height was greater than 25 Relative Luminous Unit. The reduction in peak height between samples prepared using the PyroMark Q96 Vacuum Workstation compared with PyroMark Control Oligo added directly to the PyroMark Q96 Plate Low should not be more than 20\%. Each CpG site had a quality assessments bar. Only quality assessments of all CpG sites in a well gave "Passed" quality, the methylation results could be used. The methylation levels were obtained from triplicate experiments, and the standard deviation was not exceed $2 \%$ units.

\section{Statistical analysis}

We used the median and interquartiles range to describe the basic characteristics and laboratory parameters for continuous variables, which were skewed normal distribution, and tested using Mann-Whitney $\mathrm{U}$ test. The data of categorical variables were presented as frequency and proportion and tested using Chi-square test. Correlations of each PAH metabolites and each CYP1A1 methylation sites were explored by Spearman's correlation. We evaluated the effect of smoking on urine $\mathrm{PAH}$ metabolites by calculating smoking contribution to PAH metabolite [defined as the $R^{2}$ difference between models with and without smoking]; other covariates were sex, age, years of working, drinking status, education and central heating. Logistic regression was conducted to evaluate associations of smoking and PAH metabolites co-exposure with CYP1A1 hypomethylation and high 8-OHdG. The cutoff points for CYP1A1 hypomethylation and high 8OHdG defined as the 50th percentile were equal to 3.03 and $204.05 \mathrm{mmol} / \mathrm{mol} \mathrm{Cr}$, respectively. Covariates were adjusted including sex, age, years of working, smoking and drinking status (yes or no), education $(<9,9-12,>12)$, central heating (yes or no). A logistic regression model and a test of linear trend was used to estimate associations between CYP1A1 hypomethylation and high 8-OHdG. The test for trend across decreasing tertile of CYP1A1 methylation were conducted by assigning the medians of average CYP1A1 methylation in tertiles treated as a continuous variable. Finally, we run a mediation analysis to investigate whether CYP1A1 hypomethylation mediated smoking and PAH metabolites co-exposure effect on high 8-OHdG levels. The detailed instruction of mediation analysis could be seen in Lin et al. [24]. The mediation macro in SAS 9.4 (SAS Institute Inc., Cary, NC): \%mediate (data $=, \mathrm{id}=$, outcome $=$, exposure $=$, intermed $=$, modprint $=$ $\mathrm{T}$, intmiss $=\mathrm{F}$, notes $=$ nonotes, covars $=$, modopt $=$, procopt $=$, extrav $=$, where $=, R R^{2}=1$, debugdv $=1$, surv $=0$, type $=1$ ). The mediation effect was evaluated using the mediation percentage. There were statistically significance for $P$ value $<0.05$.

\section{Results}

\section{Essential information}

Table 1 showed the essential information of occupational workers with low $(n=250)$ and high $(n=250)$ 8-OHdG levels. Among 500 individuals, there were no statistically differences in sex, education, occupation, and central heating. Workers with high 8 -OHdG were more likely to be older, longer years of working, smokers and drinkers. There were increasing trends in urine $\mathrm{PAH}$ metabolites with the 
Table 1 Essential information and laboratory parameters among 500 occupational workers

\begin{tabular}{|c|c|c|c|}
\hline Variables $^{a}$ & low 8-OHdG ( $204.05 \mathrm{mmol} / \mathrm{mol} \mathrm{Cr})$ & high 8-OHdG (> $204.05 \mathrm{mmol} / \mathrm{mol} \mathrm{Cr}$ ) & $p^{b}$ \\
\hline \multicolumn{4}{|l|}{ Sex } \\
\hline Male & $217(86.8)$ & $228(91.2)$ & \multirow[t]{2}{*}{0.116} \\
\hline Female & $33(13.2)$ & $22(8.8)$ & \\
\hline Age (years) & $39(32-45)$ & $41(37-46)$ & 0.009 \\
\hline Years of working & $20(14-27)$ & $22(17-28)$ & 0.007 \\
\hline \multicolumn{4}{|l|}{ Education (years) } \\
\hline$<9$ & $53(21.1)$ & $66(26.4)$ & \multirow[t]{3}{*}{0.273} \\
\hline $9-12$ & $92(36.8)$ & $94(37.6)$ & \\
\hline$>12$ & $105(42.0)$ & $90(36.0)$ & \\
\hline \multicolumn{4}{|l|}{ Occupation } \\
\hline Coke oven worker & $191(76.4)$ & $198(79.2)$ & \multirow[t]{2}{*}{0.451} \\
\hline Water treatment worker & $59(23.6)$ & $52(20 . .8)$ & \\
\hline \multicolumn{4}{|l|}{ Central heating } \\
\hline yes & $237(94.8)$ & $233(93.2)$ & \multirow[t]{2}{*}{0.451} \\
\hline no & $13(5.2)$ & $17(6.8)$ & \\
\hline \multicolumn{4}{|l|}{ Smoking status } \\
\hline yes & $94(37.9)$ & $132(53.2)$ & \multirow[t]{2}{*}{0.001} \\
\hline no & $154(62.1)$ & $116(46.8)$ & \\
\hline \multicolumn{4}{|l|}{ Drinking status } \\
\hline yes & $142(56.8)$ & $178(71.2)$ & \multirow[t]{2}{*}{0.001} \\
\hline no & $108(43.2)$ & $72(28.8)$ & \\
\hline 1-OHP $(\mu \mathrm{g} / \mathrm{mmol} \mathrm{Cr})$ & $0.05(0.03-0.09)$ & $0.06(0.04-0.10)$ & 0.144 \\
\hline 2-NAP $(\mu \mathrm{g} / \mathrm{mmol} \mathrm{Cr})$ & $0.65(0.36-1.07)$ & $0.79(0.44-1.25)$ & 0.007 \\
\hline 2-FLU $(\mu \mathrm{g} / \mathrm{mmol} \mathrm{Cr})$ & $0.26(0.17-0.46)$ & $0.28(0.19-0.43)$ & 0.395 \\
\hline 9-PHE ( $\mu \mathrm{g} / \mathrm{mmol} \mathrm{Cr})$ & $0.08(0.06-0.14)$ & $0.09(0.06-0.17)$ & 0.856 \\
\hline$\Sigma \mathrm{PAH}(\mu \mathrm{g} / \mathrm{mmol} \mathrm{Cr})$ & $0.27(0.18-0.46)$ & $0.34(0.23-0.48)$ & 0.014 \\
\hline \multicolumn{4}{|l|}{ CYP1A1 methylation } \\
\hline pos.1 & $2.95(0.00-4.36)$ & $2.43(0.00-4.07)$ & 0.129 \\
\hline pos.2 & $2.19(0.00-3.47)$ & $1.83(0.00-3.49)$ & 0.913 \\
\hline pos.3 & $4.83(2.24-6.17)$ & $3.92(0.00-6.00)$ & 0.055 \\
\hline pos.4 & $2.40(0.00-3.94)$ & $2.09(0.00-3.51)$ & 0.477 \\
\hline pos. 5 & $2.52(0.00-4.53)$ & $1.43(0.00-3.99)$ & 0.060 \\
\hline average & $3.10(1.63-4.20)$ & $2.42(1.29-3.85)$ & 0.031 \\
\hline
\end{tabular}

Drinking status missing 4 values

a Data were presented as n (\%) or Median (25th - 75th)

${ }^{\mathrm{b}} P$-values were calculated from Chi-square test for categorical variables and Mann-Whitney $\mathrm{U}$ test for numerical variables

increasing of urine 8-OHdG levels. And the urine 2-NAP and $\Sigma$ PAH levels were significantly differences between low and high 8 -OHdG levels $(P<0.05)$. The detailed distributions of urine PAH metabolites could be found in Additional file $1:$ Table S2. Urine PAH metabolites were related to each other (Additional file 1 :Table S3); CYP1A1 methylation at each sites were correlated with each other (Additional file 1 :Table S4), and we used average CYP1A1 methylation to represent the CYP1A1 methylation at each site. Average CYP1A1 methylation levels in workers with high 8-OHdG levels were significantly lower than in workers with low 8-OHdG levels (2.42 vs. 3.10).

\section{The co-exposure effect of smoking and urine PAH metabolites on CYP1A1 hypomethylation}

First, we tested the contribution rates of smoking on urine PAH metabolites, and found smoking accounted for 0.29\% of the $1-\mathrm{OHP}$ variance, $8.99 \%$ of the 2 -NAP variance, $0.11 \%$ 
of the 2-FLU variance, $6.37 \%$ of the 9-PHE variance and $1.99 \%$ of the $\Sigma \mathrm{PAH}$ variance (Additional file 1 :Table S5). Because of the higher contribution rates of smoking on 2NAP and 9-PHE, we chose 1-OHP and 2-FLU as biomarkers of urine PAH metabolites to explore the co-exposure effect of smoking and occupational PAH on CYP1A1 hypomethylation and high 8-OHdG.

The odds radios (ORs) and 95\% confidence intervals (CIs) for the associations of smoking and 1-OHP co-exposure with $C Y P 1 A 1$ hypomethylation were presented in Fig. 1. After adjusting covariates (i.e. sex, age, years of working, drinking status, education and central heating), we found that smoking and 1-OHP co-exposure was associated with CYP1A1 hypomethylation $(P<0.05)$. That is, smokers who had high 1-OHP levels had about 1.87 (1.01-3.47) times risk of CYP1A1 hypomethylation, compared to non-smokers who had low 1-OHP levels. The same increasing trends could be observed in smoking and 2-FLU co-exposure effects on CYP1A1 hypomethylation levels, but were not significantly difference $(P>0.05)$.
The co-exposure effect of smoking and urine $\mathrm{PAH}$ metabolites on high 8-OHdG

The ORs for association of smoking and urine $\mathrm{PAH}$ metabolites co-exposure with high $8-\mathrm{OHdG}$ were presented in Fig. 1. After adjusting covariates, we observed smokers who with high 1-OHP levels had significantly higher 8-OHdG levels compared with non-smokers who with low 1-OHP levels [OR (95\% CI): 2.13 (1.14-3.97)]. Smokers, no matter exposed to low or high levels of urine 2-FLU, had an increasing risk of high 8-OHdG levels compared with non-smokers.

\section{The association between CYP1A1 hypomethylation and high 8-OHdG}

The association between CYP1A1 hypomethylation and high 8 -OHdG could be found in Table 2. The risk of high 8 -OHdG levels was on the rise trend when the CYP1A1 methylation levels gradually decreased. The crude ORs $(95 \% C I)$ of high $8-O H d G$ for decreasing tertile of CYP1A1 methylation were 1.00 (reference), 1.24 $(0.81-1.91)$, and $1.66(1.08-2.57)$, respectively $(P$ trend $=$

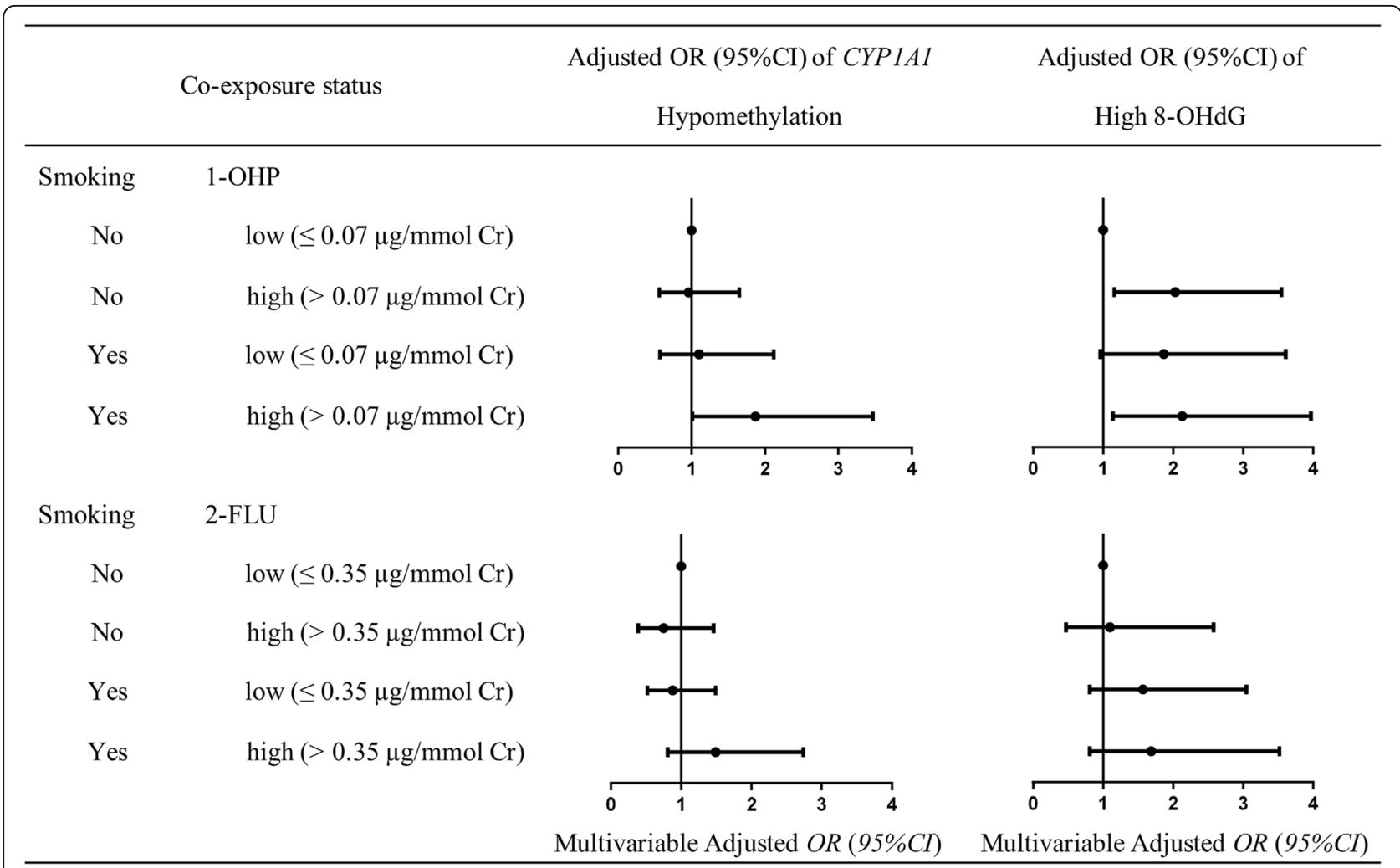

Fig. 1 Co-exposure effects of smoking and urine PAH metabolites on risk of CYP1A1 hypomethylation and high 8-OHdG. The statuses of smoking were stratified by non-smokers and smokers. The levels of urine PAH metabolites were stratified by the highest tertile into low exposure $(<67$ th percentile) and high exposure ( $\geq 67$ th percentile). The levels of CYP1A1 methylation were stratified by the median (3.03) into CYP1A1 hypomethylation $(<3.03)$ and CYP1A1 hypermethylation ( $\geq 3.03)$. The levels of urine 8-OHdG were stratified by the median $(204.05 \mathrm{mmol} / \mathrm{mol} \mathrm{Cr})$ into low 8-OHdG $(<204.05 \mathrm{mmol} / \mathrm{mol} \mathrm{Cr})$ and high 8-OHdG $(\geq 204.05 \mathrm{mmol} / \mathrm{mol} \mathrm{Cr})$. Adjusted for sex, age, years of working, drinking status, education and central heating 
Table 2 The association between CYP1A1hypomethylation and high 8-OHdG among 500 occupational workers

\begin{tabular}{llll}
\hline CYP1A1 methylation & $n$ & Crude OR $(95 \% \mathrm{Cl})$ & Adjusted ORa $(95 \% \mathrm{Cl})$ \\
\hline Tertile1 $(\leq 2.07)$ & 166 & $1.66(1.08-2.57)$ & $1.58(1.01-2.47)$ \\
Tertile2 (2.07-3.81) & 168 & $1.24(0.81-1.91)$ & $1.24(0.79-1.92)$ \\
Tertile3 (> 3.82) & 166 & 1.00 (reference) & 1.00 (reference) \\
P for trend & & 0.021 & 0.046 \\
\hline
\end{tabular}

${ }^{a}$ Multiple logistic regression with adjusted for sex, age, years of working, drinking status, education and central heating

0.021). In the lowest tertile of $C Y P 1 A 1$ methylation, the $O R$ of high $8-O H d G$ decreased to $1.58(1.01-2.47)$ when adjusting for all covariates, with $P$ for trend $=0.046$.

\section{CYP1A1 hypomethylation mediated the co-exposure effect of smoking and urine PAH metabolites on high 8- OHdG}

We performed mediation analysis of CYP1A1 hypomethylation in the association between smoking and $\mathrm{PAH}$ metabolites co-exposure and oxidative DNA damage. We observed a significant mediation effect of CYP1A1 hypomethylation in the association between smoking and 1-OHP co-exposure and high 8 -OHdG in Table 3 $(P=0.047)$. The mediation analysis showed a mediation proportion of $13.6 \%$ (95\% CI: $2.6-47.9 \%)$. These results suggested that CYP1A1 hypomethylation may be a potential mediator of smoking and 1-OHP co-exposure effect on the risk of oxidative DNA damage. However, we didn't find that the associations between smoking and 2-FLU co-exposure and high 8-OHdG were mediated by $C Y P 1 A 1$ hypomethylation.

\section{Discussion}

In this study, we observed the co-exposure effect of smoking and 1-OHP were positively associated with CYP1A1 hypomethylation and high 8-OHdG (a biomarker of oxidative damage to DNA) after adjusting for covariates. We also investigated a positive relationship between CYP1A1 hypomethylation and high 8-OHdG in an upwardly trending, dose-responsive manner. Moreover, CYP1A1 hypomethylation may serve as a potential mediator of smoking and occupational PAH co-exposure effect on risk of oxidative DNA damage.

In the current study, we also detected the concentration of environmental $\mathrm{PAH}$, since the air $\mathrm{PAH}$ levels in the plant could represent the exposure status of occupational workers. The results showed the sum PAH of the workplace was markedly lower than Kuang et al. [11]: $0.38 \mathrm{mg} / \mathrm{m}^{3}$ vs. $1.13 \mathrm{mg} / \mathrm{m}^{3}$ in the non coke-oven place, $1.45 \mathrm{mg} / \mathrm{m}^{3}$ vs. $11.08 \mathrm{mg} / \mathrm{m}^{3}$ at the side of the coke-oven. The big difference of environmental PAH exposure may account for internal exposure different. PAH internal exposure, which showed various pathways of exposure, could be more accurate to reflect the actual levels of PAH exposure. Urinary 1-OHP was a widely used shorttime biomarker of PAH exposure, and had a linear relationship with PAH concentration in the workplace [25]. But it alone cannot reflect the overall internal $\mathrm{PAH}$ metabolites, and urine hydroxylated nathalene [26], hydroxylated fluorene and hydroxylated phenanthrenes were suggested to be good surrogate biomarkers of occupational PAH exposure. Urine $\mathrm{PAH}$ metabolites were regarded as biomarkers to evaluate external PAH exposure [27]. The concentration of urine PAH metabolites in our research were lower than Kuang et al. [11] and Talaska et al.'s [28] researches. Besides external $\mathrm{PAH}$ exposure, regional differences, air pollution, lifestyle behaviors and laboratory methods can also cause the difference in urine PAH metabolites.

Some studies indicated smoking can alter the DNA methylation status [29-32]. Tekpli [18] reported smoking was associated with CYP1A1 methylation. Other studies suggested PAH exposure was related to DNA methylation [33-35]. In our study, we observed smoking and 1-OHP co-exposure was associated with CYP1A1 hypomethylation, further proved that smokers exposed to PAH were more likely to lower CYP1A1 methylation levels, which were consisted with other studies. However, the underlying mechanisms of methylation changes resulted from smoking or $\mathrm{PAH}$ exposure remain unknown. As far as CYP1A1 is concerned, we can speculate aryl hydrocarbon receptor (AHR) binding to CYP1A1 promoter region accelerated after smoking or PAH exposure, may cause the CYP1A1 methyltransferase removed from the promoter and subsequently lead to a loss of methylation. Therefore, the CYP1A1 methylation could be inducted by gene expression, but could promote the binding of AHR and strengthen transcriptional activity in return [36].

PAH can be metabolized by CYP1A1, and then generate ROS, which were known to cause oxidative DNA modification. As one of the predominant forms of oxidative lesions in DNA, 8-OHdG is a specific and quantitative biomarker of oxidative damage to DNA [37, 38].

Table 3 CYP1A1 hypomethylation mediated the effect of smoking and 1-OHP co-exposure on high 8-OHdG

\begin{tabular}{lllll}
\hline Co-exposure & Total effect & Direct effect & Proportion mediated by CYP1A1 hypomethylation & $P$ value \\
\hline Smoking and1-OHP & $1.03(1.00-1.06)$ & $1.02(1.00-1.05)$ & $13.6 \%(2.6-47.9 \%)$ & 0.047 \\
\hline
\end{tabular}

Covariates in the SAS macro include sex, age,years of working, drinking status, education and central heating

${ }^{a}$ Total effects of smoking and 1-OHP co-exposure on high 8-OHdGwere estimated without adjusting for CYP1A1hypomethylation

${ }^{\mathrm{b}}$ Direct effects of smoking and 1-OHP co-exposure on high 8-OHdG were estimated with adjusting for CYP1A1hypomethylation 
Urine 8-OHdG is highly affected by many factors, such as sex, age, smoking, occupational exposure, and so on. Some studies had showed PAH exposure was positively related to urine 8-OHdG whether in the occupational worker or general population [14, 39, 40]. Asami et al. [9] showed a significant relationship between the Brinkman index and 8-OHdG levels. Our study revealed smoking and 1-OHP co-exposure was positively related to high 8-OHdG levels, indicating smokers, which are occupational exposed to $\mathrm{PAH}$ in the long term, may have more serious oxidative damage to DNA. These results were consistent with the previously reported findings [15].

Even though the smoking and 1-OHP co-exposure plays an important role in the high 8-OHdG levels, a challenge remains to provide a functional interpretation and investigate the further mechanism of smoking and $\mathrm{PAH}$ exposure on the development of oxidative damage to DNA. Some studies reported that gene methylation was associated with DNA damage [10, 35, 41]. We also showed a dose-responsive relationship between CYP1A1 hypomethylation and high 8-OHdG levels. These findings add to the strength of relationship between DNA methylation and oxidative DNA damage. DNA methylation, which can reflect the co-exposure between environmental factors, could be a possible "missing link" and is an attractive mechanism to explain the formation of oxidative damage to DNA. The mediation analysis suggested that $13.6 \%$ effect of oxidative DNA damage related to smoking and 1-OHP co-exposure was mediated by CYP1A1 hypomethylation, indicating that smoking and $\mathrm{PAH}$ co-exposure may influence oxidative damage to DNA through CYP1A1 hypomethylation. In fact, it has been established that CYP1A1 expression is important in the metabolic process of xenobiotic and CYP1A1 mRNA levels correlate with DNA damage levels $[42,43]$. Since the gene methylation plays a pivotal role in regulating expression, a compellent viewpoint is the epigenetic regulation of CYP1A1 expression may be an important factor in xenobiotic-related to oxidative DNA damage. The altered DNA methylation in promoter region, which may influence assembly and gene expression of CYP1A1, could influence PAH metabolic process in vivo, eventually lead to the oxidative DNA damage.

Nevertheless, our study also has some limitations. For the nature of cross-sectional, our results cannot establish a causal association between PAH exposure, CYP1A1 hypomethylation and oxidative DNA damage. Besides, urine cotinine levels as a specific biomarker of smoking, body mass index, physical activity, eating habits, etc., which can affect the urine 1-OHP and 8-OHdG concentration, and white blood cell subtype, which may have an impact on DNA methylation, weren't duly taken into account. Finally, the smaller sample size and relatively less biomarkers of PAH exposure are the shortages for our study. Nevertheless, we still observed the co-exposure effect of smoking and 1-OHP on oxidative DNA damage was partly mediated by CYP1A1 hypomethylation. We didn't find that CYP1A1 hypomethylation mediated the co-exposure effect of smoking and 2-FLU on oxidative DNA damage. One potential explanation is that the most representative metabolites of $\mathrm{PAH}$ exposure in urine were 1-OHP for occupational workers in coke oven plants. Many studies suggested that 1-OHP was a suitable $\mathrm{PAH}$ internal exposure biomarker in coke-oven workers $[28,44]$, which was further confirmed by our results. In addition, there may be other pathways involved to further research.

\section{Conclusions}

In this study, we quantitative assessed the association of smoking and occupational PAH co-exposure with both CYP1A1 hypomethylation and oxidative damage to DNA in Chinese occupational workers. We observed CYP1A1 hypomethylation may partly mediate the co-exposure effect of smoking and occupational $\mathrm{PAH}$ on oxidative DNA damage for the first time. From the point of public health, further prospective researches are necessary.

\section{Additional file}

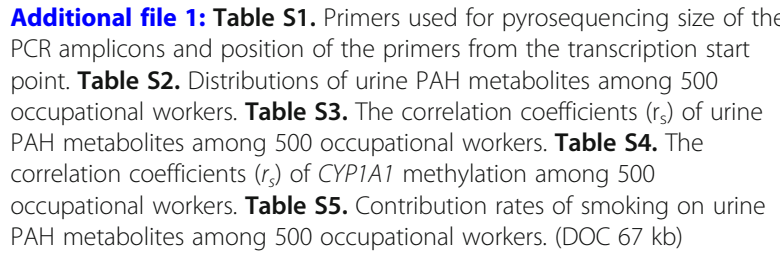

Additional file 1: Table S1. Primers used for pyrosequencing size of the PCR amplicons and position of the primers from the transcription start point. Table S2. Distributions of urine PAH metabolites among 500 occupational workers. Table S3. The correlation coefficients $\left(r_{s}\right)$ of urine PAH metabolites among 500 occupational workers. Table S4. The correlation coefficients $\left(r_{s}\right)$ of CYP1A1 methylation among 500 occupational workers. Table S5. Contribution rates of smoking on urine PAH metabolites among 500 occupational workers. (DOC 67 kb)

\section{Abbreviations}

1-OHP: 1-hydroxypyrene; 2-FLU: 2-hydroxyfluorene; 2-NAP: 2hydroxynaphthalene; 8-OHdG: 8-hydroxy-2'-deoxyguanosine; 9-PHE: 9hydroxyphenanthrene; AHR: Aryl hydrocarbon receptor; $\mathrm{Cl}$ : Confidence interval; Cr: Creatinine; CV: Coefficient of variation; CYP1A1: Cytochrome P4501A1; LOD: Limit of detection; PAH: Polycyclic aromatic hydrocarbons; PCR: Polymerase Chain Reaction; ROS: Reactive oxygen species

\section{Acknowledgements}

We are grateful for Steel Group General Hospital of Taiyuan for their helps in collecting biological sample and interviewing the study population participants.

\section{Authors' contributions \\ Jin Yang conceived and designed the current study and, with Jisheng Nie, guided the work. Yanli Liu, Hongjie Zhang, Huitao Zhang, Ye Fu, Yingying Niu, Xuejing Li, Bin Zhang contributed to the acquisition, analysis and interpretation of data. Yanli Liu drafted the manuscript, Aimin Yang and Jin Yang revised it. All authors have read and approved the final text.}

\section{Funding}

This work was supported by National Nature Science Foundation of China [No. 81273041] and Natural Science Foundation of Shanxi Province of China [No. 201701D121146]. 


\section{Availability of data and materials}

The data that support the findings of this study are available from the corresponding author upon reasonable request.

\section{Ethics approval and consent to participate}

The study was approved by the Medical Ethics Committee of the Shanxi Medical University.

\section{Consent for publication}

Not applicable.

\section{Competing interests}

The authors declare that they have no competing interests.

\section{Author details}

${ }^{1}$ Department of Occupational Health, School of Public Health, Shanxi Medical University, Taiyuan, Xinjiannan Road 56, Taiyuan 030001, Shanxi, China. ${ }^{2}$ Department of Preventive Medicine, School of Public Health and Management, Hubei University of Medicine, Shiyan, Hubei, China. ${ }^{3}$ Hong Kong Institute of Diabetes and Obesity, the Chinese University of Hong Kong, Hong Kong SAR, People's Republic of China.

Received: 3 April 2019 Accepted: 22 July 2019

Published online: 29 July 2019

\section{References}

1. Gackowski D, Speina E, Zielinska M, Kowalewski J, Rozalski R, Siomek A Paciorek T, Tudek B, Olinski R. Products of oxidative DNA damage and repair as possible biomarkers of susceptibility to Lung Cancer. Cancer Res. 2003;63: 4899-902.

2. Hecht SS. Tobacco smoke carcinogens and lung cancer. J Natl Cancer Inst 1999:91:1194-210

3. Cadet J, Berger M, Douki T, Ravanat JL. Oxidative damage to DNA: formation, measurement, and biological significance. Rev Physiol Biochem Pharmacol. 1997:131:1-87.

4. Kasai $\mathrm{H}$. What causes human cancer? Approaches from the chemistry of DNA damage Genes Environ. 2016;38:19.

5. Murugaiyan SB, Ramasamy R, Nakkeeran M, Rangdhol V, Srinivasan AR, Niranjan G. Urinary 8-hydroxydeoxyguanosine as a marker of oxidative stress induced genetic toxicity in oral cancer patients. Indian J Dent Res. 2015;26: 226-30

6. Pilger A, Rüdiger HW. 8-Hydroxy-2'-deoxyguanosine as a marker of oxidative DNA damage related to occupational and environmental exposures. Int Arch Occup Environ Health. 2006:80:1-15.

7. Peña N, Carrillo D, Muñoz JP, Chnaiderman J, Urzúa U, León O, Tornesello ML, Corvalán AH, Soto-Rifo R, Aguayo F. Tobacco smoke activates human papillomavirus 16 p97 promoter and cooperates with high-risk E6/E7 for oxidative DNA damage in Lung cells. PLoS One. 2015;10:e0123029.

8. Sarker AH AC, Monique Williams, Sabrina Lin, Christopher Havel, Peyton Jacob III, Istvan Boldogh, Tapas K. Hazra, Prudence Talbot, Bo Hang. NEIL2 Protects against Oxidative DNA Damage Induced by Sidestream Smoke in Human Cells. PLoS One 2014;9:e90261.

9. Asami S, Manabe H, Miyake J, Tsurudome $Y$, Hirano $T$, Yamaguchi R, Itoh $H_{\text {, }}$ Kasai $\mathrm{H}$. Cigarette smoking induces an increase in oxidative DNA damage, 8-hydroxydeoxyguanosine, in a central site of the human lung. Carcinogenesis. 1997;18:1763-6.

10. Alvarado-Cruz I, Sánchez-Guerra M, Hernández-Cadena L, De V-RA, Mugica V, Pelallo-Martínez NA, Solís-Heredia MJ, Byun HM, Baccarelli A, QuintanillaVega B. Increased methylation of repetitive elements and DNA repair genes is associated with higher DNA oxidation in children in an urbanized, industrial environment. Mutat Res. 2016:813:27.

11. Kuang D, Zhang W, Deng Q, Zhang X, Huang K, Guan L, Hu D, Wu T, Guo $H$. Dose-response relationships of polycyclic aromatic hydrocarbons exposure and oxidative damage to DNA and lipid in coke oven workers. Environ Sci Technol. 2013;47:7446-56

12. Bagryantseva $Y$, Novotna B, Jr PR, Chvatalova I, Milcova A, Svecova V, Lnenickova Z, Solansky I, Sram RJ. Oxidative damage to biological macromolecules in Prague bus drivers and garagemen: impact of air pollution and genetic polymorphisms. Toxicol Lett. 2010;199:60-8.
13. Sanghyuk B, Pan XC, Suyoung K, Kwangsik P, Yoonhee K, Ho K, Hong YC. Exposures to particulate matter and polycyclic aromatic hydrocarbons and oxidative stress in schoolchildren. Environ Health Perspect. 2010;118:579-83.

14. Hong YC, Park EY, Park MS, Ko JA, Oh SY, Kim H, Lee KH, Leem JH, Ha EH. Community level exposure to chemicals and oxidative stress in adult population. Toxicol Lett. 2009;184:139-44.

15. Yang J, Zhang H, Zhang H, Wang W, Liu Y, Fan Y. Smoking modify the effects of polycyclic aromatic hydrocarbons exposure on oxidative damage to DNA in coke oven workers. Int Arch Occup Environ Health. 2017;90:1-9.

16. Shimada T, Martin MV, Pruess-Schwartz D, Marnett LJ, Guengerich FP. Roles of individual human cytochrome P-450 enzymes in the bioactivation of benzo(a)pyrene, 7,8-dihydroxy-7,8-dihydrobenzo(a)pyrene, and other dihydrodiol derivatives of polycyclic aromatic hydrocarbons. Cancer Res. 1989:49:6304-12.

17. Stohs SJ. Oxidative stress induced by 2,3,7,8-tetrachlorodibenzo-p-dioxin (TCDD). Free Radic Biol Med. 1990;9:79-90.

18. Tekpli X. DNA methylation of the CYP1A1 enhancer is associated with smoking-induced genetic alterations in human lung. Int J Cancer. 2012; 131:1509-16.

19. Stücker I, Jacquet $M$, De Wl, Cénée $S$, Beaune $P$, Kremers $P$, Hémon D. Relation between inducibility of CYP1A1, GSTM1 and lung cancer in a French population. Pharmacogenetics. 2000;10:617-27.

20. Wu MT, Mao IF, Ho CK, Wypij D, Lu PL, Smith TJ, Chen ML, Christiani DC Urinary 1-Hydroxypyrene concentrations in coke oven workers. Occup Environ Med. 1998;55:461-7.

21. Kim H, Cho SH, Kang JW, Kim YD, Nan HM, Lee CH, Lee H, Kawamoto T. Urinary 1-hydroxypyrene and 2-naphthol concentrations in male Koreans. Int Arch Occup Environ Health. 2001;74:59.

22. Elovaara E, Väänänen V, Mikkola J. Simultaneous analysis of naphthols, phenanthrols, and 1-hydroxypyrene in urine as biomarkers of polycyclic aromatic hydrocarbon exposure: intraindividual variance in the urinary metabolite excretion profiles caused by intervention with $\beta$-naphthoflavone. Arch Toxicol. 2003;77:183-93.

23. Yuan J, Chen L, Chen D, Guo H, Bi X, Ju Y, Jiang P, Shi J, Yu Z, Yang J. Elevated serum polybrominated diphenyl ethers and thyroid-stimulating hormone associated with lymphocytic micronuclei in Chinese workers from an E-waste dismantling site. Environ Sci Technol. 2008;42:2195-200.

24. Lin DY, Fleming TR, De Gruttola V. Estimating the proportion of treatment effect explained by a surrogate marker. A Jane Austen education. 1997.

25. Campo L, Rossella F, Pavanello S, Mielzynska D, Siwinska E, Kapka L, Bertazzi PA, Fustinoni S. Urinary profiles to assess polycyclic aromatic hydrocarbons exposure in coke-oven workers. Toxicol Lett. 2010;192(1):72-8.

26. Fan R, Wang D, Mao C, Ou S, Lian Z, Huang S, Lin Q, Ding R, She J. Preliminary study of children's exposure to PAHs and its association with 8-hydroxy-2'-deoxyguanosine in Guangzhou. China Environ Int. 2012;42:53-8.

27. Scherer G, Frank S, Riedel K, Megerkossien I, Renner T. Biomonitoring of exposure to polycyclic aromatic hydrocarbons of nonoccupationally exposed persons. Cancer Epidemiol Biomark Prev. 2000;9:373-80.

28. Talaska G, Thoroman J, Schuman B. Kãafferlein HU. Biomarkers of polycyclic aromatic hydrocarbon exposure in European coke oven workers. Toxicol Lett. 2014;231:213-6.

29. Harlid S, Xu Z, Panduri V, Sandler DP, Taylor JA. CpG sites associated with cigarette smoking: analysis of epigenome-wide data from the sister study. Environ Health Perspect. 2014;122:673-8.

30. Markunas CA, Xu Z, Harlid S, Wade PA, Lie RT, Taylor JA, Wilcox AJ. Identification of DNA methylation changes in newborns related to maternal smoking during pregnancy. Environ Health Perspect. 2014;122:1147-53.

31. Lee KW, Richmond R, Hu P, French L, Shin J, Bourdon C, Reischl E Waldenberger M, Zeilinger S, Gaunt T. Prenatal exposure to maternal cigarette smoking and DNA methylation: epigenome-wide association in a discovery sample of adolescents and replication in an independent cohort at birth through 17 years of age. Environ Health Perspect. 2015;70:193-9.

32. Zhu X, Li J, Deng S, Yu K, Liu X, Deng Q, Sun H, Zhang X, He M, Guo H. Genome-wide analysis of DNA methylation and cigarette smoking in a Chinese population. Environ Health Perspect. 2016;124:966-73.

33. Yang J, Liu Y, Zhang H, Zhang H, Wang W, Fan Y. Urinary 1-hydroxypyrene and smoking are determinants of LINE-1 and AhRR promoter methylation in coke oven workers. Mutat Res. 2018;826:33-40.

34. Yang $P$, Gong YJ, Cao WC, Wang RX, Wang YX, Liu C, Chen YJ, Huang LL, A $\mathrm{SH}, \mathrm{Lu}$ WQ. Prenatal urinary polycyclic aromatic hydrocarbon metabolites, 
global DNA methylation in cord blood, and birth outcomes: a cohort study in China. Environ Pollut. 2018;234:396-405.

35. Herbstman JB, Tang D, Zhu D, Qu L, Sjödin A, Li Z, Camann D, Perera FP. Prenatal exposure to polycyclic aromatic hydrocarbons, benzo[a]pyreneDNA adducts, and genomic DNA methylation in cord blood. Environ Health Perspect. 2012;120:733-8.

36. Shen ES, Jr WJ. The potential role of DNA methylation in the response to 2,3,7,8-tetrachlorodibenzo-p-dioxin. J Biol Chem. 1989;264:17754-8.

37. Musarrat J, Arezina-Wilson J, Wani AA. Prognostic and aetiological relevance of 8-hydroxyguanosine in human breast carcinogenesis. Eur J Cancer. 1996; 32A(7):1209-14.

38. Chiou CC, Chang PY, Chan EC, Wu TL, Tsao KC, Wu JT. Urinary 8hydroxydeoxyguanosine and its analogs as DNA marker of oxidative stress: development of an ELISA and measurement in both bladder and prostate cancers. Clin Chim Acta. 2003:334(1-2):87-94.

39. Sauvain JJ, Setyan A, Wild P, Tacchini P, Lagger G, Storti F, Deslarzes S, Guillemin M, Rossi MJ, Riediker M. Biomarkers of oxidative stress and its association with the urinary reducing capacity in bus maintenance workers. J Occup Med Toxicol. 2011;6(1):18.

40. Lee MW, Chen ML, Lung SC, Tsai CJ, Lai CF, Yang SC, Mao IF. Increase of urinary concentrations of 8-hydroxy-2'-deoxyguanosine in diesel exhaust emission inspector exposed to polycyclic aromatic hydrocarbons. Int Arch Occup Environ Health. 2012;85:273-82.

41. Shen ML, He ZN, Zhang X, Duan HW, Niu Y, Bin P, Ye M, Meng T, Dai YF, Yu SF. Association of etheno-DNA adduct and DNA methylation level among workers exposed to diesel engine exhaust. Zhonghua Yu Fang Yi Xue Za Zhi. 2017;51(6):556-61.

42. Mollerup S, Berge G, Baera R, Skaug V, Hewer A, Phillips DH, Stangeland L, Haugen A. Sex differences in risk of lung cancer: expression of genes in the PAH bioactivation pathway in relation to smoking and bulky DNA adducts. Int J Cancer. 2006;119(4):741-4.

43. Uppstad H, Øvrebø S, Haugen A, Mollerup S. Importance of CYP1A1 and CYP1B1 in bioactivation of benzo[a]pyrene in human lung cell lines. Toxicol Lett. 2010;192:221-8.

44. Duan H, Leng S, Pan Z, Dai Y, Niu Y, Huang C, Bin P, Wang Y, Liu Q, Chen W. Biomarkers measured by cytokinesis-block micronucleus cytome assay for evaluating genetic damages induced by polycyclic aromatic hydrocarbons. Mutat Res. 2009;677:93-9.

\section{Publisher's Note}

Springer Nature remains neutral with regard to jurisdictional claims in published maps and institutional affiliations.

Ready to submit your research? Choose BMC and benefit from:

- fast, convenient online submission

- thorough peer review by experienced researchers in your field

- rapid publication on acceptance

- support for research data, including large and complex data types

- gold Open Access which fosters wider collaboration and increased citations

- maximum visibility for your research: over $100 \mathrm{M}$ website views per year

At $\mathrm{BMC}$, research is always in progress.

Learn more biomedcentral.com/submissions 